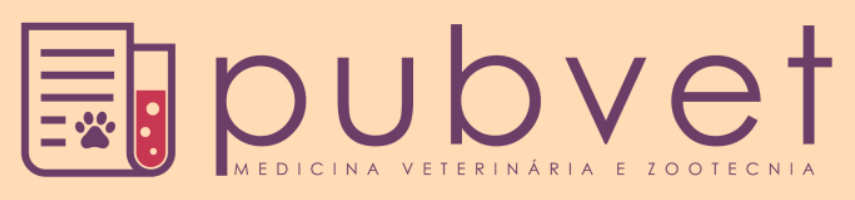

https://doi.org/10.31533/pubvet.v12n8a160.1-3

\title{
Análise temporal da dieta de Athene cunicularia em Brasília-DF
}

\author{
Ana Clara de Souza Terce Santana Martinez ${ }^{*}$, Geraldo de Brito Freire Júnior $^{20}$ \\ ${ }^{I}$ Aluna do Curso de Medicina Veterinária da Faculdade ICESP e Bolsista de Iniciação Científica E-mail: anaterce@hotmail.com \\ ${ }^{2}$ Professor Doutor do Curso de Medicina Veterinária e Orientador de Iniciação Científica da Faculdade ICESP e das Faculdades Integradas \\ Promove de Brasília - E-mail: geraldo.freire@icespe.edu.br \\ *Autor para correspondência
}

RESUMO. Athene cunicularia é uma ave cosmopolita, nidificam em solos inclinados e sem vegetação. Ao alimentar-se regurgitam o conteúdo não digerido em pelotas denominadas egagrópilas. A análise das egagrópilas é um método não invasivo e permite estabelecer a dieta de maneira eficiente. Este estudo investigou a variação na dieta de $A$. cunicularia em duas estações climáticas (seca: maio a junho/17 e chuvosa: dezembro/16 e janeiro/17). As egagrópilas coletadas foram armazenadas em sacos plásticos e levados ao laboratório para triagem do conteúdo. Foram encontrados 80 indivíduos, distribuídos em cinco categorias taxonômica. Os insetos contribuem com aproximadamente $80 \%$ da dieta (Coleópteros: $56 \%$ e Blattaria $22 \%$.), variando de $67 \%$ na época seca à $92 \%$ na época chuvosa. Itens pouco frequentes como pequenos vertebrados (12\%) e larvas de Tenébrio (8\%) ocorreram em maior número e foram restritos à estação seca. Um balanço entre abundância e teor nutricional oferecido por esses insetos é um potencial fator para o padrão observado. As estações climáticas influenciam as distribuições das espécies animais e isso se torna evidente na dieta dessa coruja. A menor disponibilidade de insetos durante o período seco contribui para o aumento na utilização dos demais itens alimentares verificados nessa estação.

Palavras chave: amplitude de dieta, coruja, egagrópilas, animais silvestres

\section{Temporal analysi sof the diet of Athene cunicularia in Brasilia-DF}

ABSTRACT. Athene cunicularia is a cosmopolitan owl, their nest is present in bare soil. A. cunicularia regurgitates the non-digest material, and the analysis of this material allow an accurate investigation of their diet in a non-invasive way. This study described the temporal variation on the diet content of this owl in two season (dry and rain season). The samples were collected in two climatic periods (dry: May to June and wet: December to January) and were stored in zip bags previously tagged with all sample information. The diet contend was identified as morphotypes. It was verified 80 individuals distributed in five taxonomic groups. In general insects contributes with $80 \%$ of A. cunicularia diet (Coleoptera-56\%; Battaria: 22\%). Insect consumption was higher in wet season (92\%) and lower in the dry season (67\%), period that this owl uses small vertebrates $(12 \%)$ and tenebios larvae (8\%) as well. A tradeoff between the abundance and the nutritional value of each item is an important factor to explain the temporal variation in the A. cunicularia diet. The climatic factors influence the fauna and it is evidenced in the diet analysis. On the dry season, period of lower insect abundance, others items were used by this owl.

Keywords: Ergagropila, diet-breadht, owl, wild animals 


\title{
Análisis temporal de la dieta de Athene Cunicularia en Brasilia-DF
}

\begin{abstract}
Athene cunicularia es un ave cosmopolita, nidifican en suelos inclinados y sin vegetación. $\mathrm{Al}$ alimentarse regurgita el contenido no digerido en pelotas denominadas egagrópilas. El análisis de las egagrópilas es un método no invasivo y permite establecer la dieta de manera eficiente. Objetivo: Este estudio investiga la variación en la dieta de la A. cunicularia en dos estaciones climáticas (seca: may-jun/17 y lluviosa: diez/16-ene/17). Materiales y Métodos: Las egagrópilas recolectadas fueron almacenadas en bolsas plásticas y llevadas al laboratorio para clasificar el contenido. Resultados: Se encontraron 80 individuos, distribuidos en cinco categorías taxonómicas. Los insectos contribuyen con aproximadamente el $80 \%$ de la dieta (Coleópteros: $56 \%$ y Blattaria $22 \%$.), variando del $67 \%$ en la época seca al $92 \%$ en la época lluviosa. Los ítems poco frecuentes como pequeños vertebrados (12\%) y larvas de Tenébrio (8\%) ocurrieron en mayor número y se restringieron a la estación seca, respectivamente. Conclusión: Un balance entre abundancia y contenido nutricional ofrecido por estos insectos es un potencial factor para el estándar observado. Las estaciones climáticas influencian las distribuciones de las especies animales y esto se hace evidente en la dieta de ese búho. La menor disponibilidad de insectos durante el período seco contribuí en el aumento en la utilización de los demás ítems alimentarios verificados en esa estación.
\end{abstract}

Palabra clave: amplitud de dieta, búho ergagropila, animales silvestres

\section{Introdução}

Conhecida como coruja-buraqueira, Athene cunicularia possui uma capacidade de adaptação, a qual a possibilita alternar sua dieta de acordo com localização e variação temporal. A maioria das aves de rapina produzem egagrópilas que são regurgitações do conteúdo estomacal não digerido. As corujas não têm papo e a formação de pelotas é uma necessidade vital para estas aves (Sick 1997). Com isso, torna-se importante o estudo que avalia sua alimentação de acordo com o fator clima em ambiente urbano de Brasília-DF. $\mathrm{Na}$ medicina veterinária faz-se necessário a pesquisa, para avaliar os itens encontrados na dieta do rapinante, o que auxilia no manejo ideal de tratamento da mesma. Por serem predadoras do mais alto nível trófico, as corujas possuem grande importância nos ecossistemas que habitam (Burton 1973; Jaksić \& Marti 1981).

O presente estudo teve como objetivo analisar a composição alimentar das egagrópilas encontradas no meio urbano do Distrito Federal ao longo de um ano.

\section{Material e Métodos}

O estudo foi desenvolvido no Plano Piloto DF, durante o período de agosto de 2016 a junho de 2017. Ninhos foram mapeados ao longo da rodovia DF-002 (Eixão) e visitados mensalmente para observação de habitat e coleta das egagrópilas.
O material recolhido foi armazenado em sacos plásticos previamente identificados e, posteriormente triados em morfoespécies no laboratório de microscopia do ICESP PROMOVE. Foram utilizados os seguintes materiais para a triagem e análise das egagrópilas:

- Pinça anatômica

- Pinça de ponta inclinada

- $\quad$ Placa de Petri

- Lupa estereoscópica

Foi construída uma planilha com as frequências de ocorrência dos itens na dieta de $A$. cuniculariae os valores apresentados em porcentagem. Não houve aplicação de testes de hipótese.

\section{Resultados e Discussão}

Foram encontrados 80 indivíduos, distribuídos em cinco categorias taxonômica. De modo geral, $80 \%$ da dieta de A. cunicularia é composta por insetos (Coleópteros, 56\% e Blattaria, 22\%.). Entretanto, a presença dos insetos na dieta dessa coruja oscila de $67 \%$ na época seca a $92 \%$ na época chuvosa. Itens pouco frequentes como pequenos vertebrados (12\%) e larvas de Tenébrio (8\%) ocorreram em maior número e foram restritos à estação seca, respectivamente (Figura 1),

Silva et al. (2011) indicam os meses de setembro a dezembro (início da estação chuvosa) como o período de maior abundância de insetos em geral e, especialmente, os coleópteros. 
Seguido por uma drástica redução em abundância da maioria das ordens de insetos na estação seca. Isso é percebido na distribuição dos itens alimentares na dieta de $A$. cunicularia.

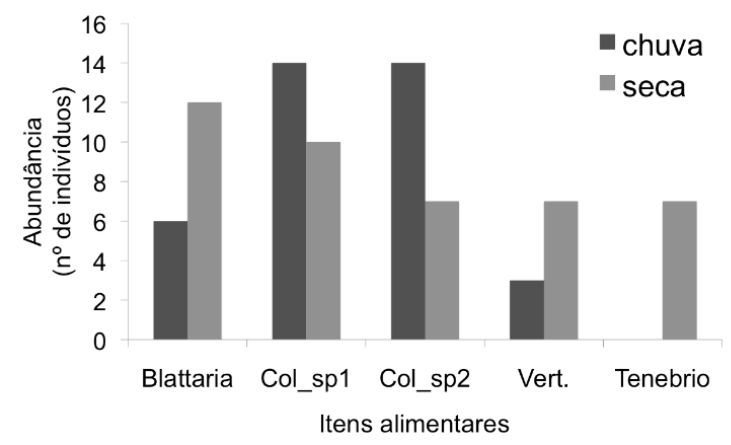

Figura 1. Frequência dos itens alimentares encontrados na dieta de A. cunicularia em dois períodos climáticos (seca e chuva).

As mudanças graduais no clima (umidade e temperatura) que ocorrem do final da seca (setembro) ao início da estação chuvosa (dezembro), coincidem com o pico de produção foliar e flores no cerrado. Folhas novas contém menos toxinas, são mais macias e com maior teor nutricional, e os insetos estão sincronizados com a distribuição desses recursos nesse período.

O padrão de dieta de $A$. cunicularia encontrado no presente estudo corrobora com estudos prévios (Motta-Junior \& Alho 1998; Motta-Junior et al. 2004; Bastian et al. 2008) e com a distribuição temporal dos insetos no cerrado (Silva et al. 2011).

\section{Conclusão}

Maior parte da dieta de A. cunicularia é composta por coleópteros. Há uma maior contribuição de vertebrados na dieta dessa coruja na estação seca, período que coincide com a menor incidência de insetos, principalmente coleópteros.

\section{Agradecimentos}

Ao Núcleo Interdisciplinar de Pesquisa pela bolsa de iniciação científica, à instituição de ensino ICESP PROMOVE por ter liberado acesso ao laboratório de microscopia para o uso dos instrumentos necessários para a pesquisa. Pelo apoio em campo, agradecemos à Mirian de Souza Terce e Daniel Leite Flores que colaboraram no monitoramento dos ninhos e coletas das egagrópilas.

\section{Referências Bibliográficas}

Bastian A.M.S., Fraga E.D., Mäder A., Garcia S.A. \& Sander M. 2008. Análise de egagrópilas de coruja-buraqueira, Athene cunicularia (Molina, 1782) no Câmpus da UNISINOS, São Leopoldo-RS (Strigiformes: Strigidae). Biodiversidade Pampeana 6, 70-3.

Burton J.A. 1973. Owls of the world: their evolution, structure and ecology. In: Ornitologia brasileira (ed. by H. S), p. 216 p. Nova Fronteira, New York.

Jaksić F.M. \& Marti C.D. 1981. Trophic ecology of Athene owls in Mediterranean-type ecosystems: a comparative analysis. Canadian journal of zoology 59, 2331-40.

Motta-Junior J.C. \& Alho C.J.R. 1998. Corujas: o que elas comem? Ciência Hoje 23, 60-2.

Motta-Junior J.C., Bueno A.A. \& Braga A.C.R. 2004. Corujas brasileiras. Instituto de Biociências da Universidade de São Paulo, São Paulo, Brasil.

Sick H. 1997. Ornitologia Brasileira. Nova Fronteira, Rio de Janeiro, Brasil.

Silva N.A.P., Frizzas M.R. \& Oliveira C.M. 2011. Seasonality in insect abundance in the" Cerrado" of Goiás State, Brazil. Revista Brasileira de Entomologia 55, 79-87.

Recebido: 10 Jul. 2018.

Aprovado: 26 Jul. 2018

Publicado: 1 Ago. 2018

Licenciamento: Este artigo é publicado na modalidade Acesso Aberto sob a licença Creative Commons Atribuição 4.0 (CC-BY 4.0), a qual permite uso irrestrito, distribuição, reprodução em qualquer meio, desde que o autor e a fonte sejam devidamente creditados. 